\title{
Brain Death and the Persistent Vegetative State: Similarities and Contrasts
}

\author{
Bryan Young, Warren Blume and Abbyann Lynch
}

\begin{abstract}
Brain death and the persistent vegetative state (PVS) share the following features: 1.) There is death of neurons in the brain; 2.) Both require an etiology which is capable of causing neuronal death. 3.) The potential for cognition is totally and permanently lost; 4.) Intensive medical support is usually withdrawn. In contrast, the diagnosis of brain death depends on death of the brainstem, while PVS implies permanent and total loss of forebrain function. While brainstem death can be diagnosed clinically, accurate prognosis in PVS requires additional investigation. Thus far, the EEG is the most specific test of neuronal function in the cerebral cortex. Brain death is equivalent to death, while PVS is not; management of the latter is more complex because of medical, social, ethical and legal factors.
\end{abstract}

RÉSUMÉ: La mort cérébrale et l'état at végétatif persistant: similitudes et contrastes Les éléments suivants sont communs à la mort cérébrale et à l'état végétatif persistant (PVS): 1) Il y a mort neuronale dans le cerveau. 2) Les deux nécessitent une étiologie capable de causer la mort de neurones. 3) Le potentiel cognitif (individualité) est totalement et irrémédiablement perdu. 4) Les mesures d'appui médical intensives sont habituellement supprimées. Par contre, le diagnostic de mort cérébrale dépend de la mort du tronc cérébral, alors que le PVS implique une perte totale et permanente de fonction du prosencéphale; la mort du tronc cérébral peut être diagnostiquée cliniquement, tandis que pour le PVS, un pronostic exact nécessite une investigation. À date, l’EEG est l'épreuve la plus spécifique de la fonction neuronale du cortex cérébral. La mort cérébrale est équivalente à la mort, alors que le PVS ne l'est pas; la conduite à tenir dans le second cas est plus complexe à cause de facteurs médicaux, sociaux, éthiques et légaux.

Can. J. Neurol. Sci. 1989; 16:388-393

Apart from death of the body as a whole, neurological conditions which physicians have accepted as justification for noninitiation or withdrawal of vigorous medical support include brain death and the persistent vegetative state (PVS). Although these entities share several features, there are essential differences. This paper examines the definitions, underlying concepts, criteria and management of each condition. We hope it will stimulate the development of better guidelines for establishing the prognosis and management of patients with severe brain insults.

\section{Brain Death}

Death can be defined as the irreversible loss of function of the organism as a whole. ${ }^{1}$ This definition encompasses biological death of all the cells of the body or, alternatively, death of the brain. 1,2 In the concept of brain death, then, death of the brain is equivalent to death of the individual. ${ }^{2}$ Reliable clinical criteria, a standardized set of qualifying conditions and tests, have been developed which, when satisfied, are reliable in assuring that the brain is dead. ${ }^{3}$ The "physiological kernel" of brain death is death of the brainstem, since its destruction produces the required permanent apneic coma with cranial nerve areflexia. ${ }^{4}$ If the criteria established in the Guidelines ${ }^{3}$ are all met, the physician, the family, and society can be assured that no purpose is served by artificially maintaining ventilation and supporting the circulation; that is, in effect, to "ventilate a corpse". 4

The concept that brain death is equivalent with death has allowed the performance of organ transplantation or the termination of support measures.

From the Department of Clinical Neurological Sciences (B.Y., W.B.) and the Westminster Institute for Ethics and Human Values (A.L.), University of Western Ontario, London

Received April 11, 1989. Accepted in final form July 29, 1989

Reprint requests to: Dr. G.B. Young, Department of Clinical Neurological Sciences, Victoria Hospital, 375 South St., London, Ontario, Canada N6A 4G5 


\section{Persistent Vegetative State}

Intractable coma can only occur if the components of the ascending reticular activating system are irreversibly destroyed, eliminating the possibility of consciousness, arousal and wakesleep cycles, yet sparing brainstem and diencephalic centres for respirations and homeostatic functions. ${ }^{5}$ Intractable coma is extremely rare; sleep-like unarousability almost never persists more than two to four weeks (see below), but evolves into the vegetative state. 6

Jennett and Plum 7 carefully chose the term "persistent vegetative state" (essentially synonymous but less commonly used labels include coma vigil, akinetic mutism, the apallic syndrome, neocortical death and total dementia) to define a clinical syndrome in which the patient, after initial coma, regains arousability in the sense of eye opening on stimulation. However, there is no evidence of cognition: the individual makes no meaningful interaction with the environment. There is no evidence of recognition. The individual appears incapable of thought, reason, memory, speech, affect or any qualities which are conventionally characteristic of human nature or personhood. ${ }^{8}$ There is typically a return of wake and sleep cycles, which, like arousability, depend upon a functioning diencephalon and brainstem tegmentum. The patient may have wandering, conjugate eye movements, but sustained visual pursuit does not occur.

In contrast with brainstem death, PVS is associated with severe and irreversible damage to the cerebrum with or without the diencephalon, $9,10,11$ while many brainstem functions, such as breathing, chewing, swallowing and cranial nerve reflexes, are largely preserved.

The prevalence of the persistent vegetative state in the United States is conservatively estimated to be between 5,000 to 10,000 ; this is expected to increase with time..$^{5}$ It is, thus, a significant medical and social problem. 12

\section{Prognosis of the Persistent Vegetative State}

Some individuals have recovered cognitive function several months or more after a clinical diagnosis of PVS was made. ${ }^{13,14,15}$ Because of the management implications of the diagnosis of PVS, it is vital that the prognosis be accurately established. Guidelines must be set to identify those who have no chance of recovery, that is those in a permanent vegetative state. How can the extent and severity of the damage be determined? Assessment is more difficult than in the determination of brain death, in which one assesses well-defined cranial nerve reflexes, respirations and reactivity, all of which are intact in the persistent vegetative state.

A priori, the condition causing this syndrome should be capable of destroying forebrain structures to an extent that these structures will have totally and permanently lost their function. Thus, conditions which are by nature potentially reversible, such as many intoxications, hypothermia, sepsis and numerous metabolic conditions (e.g. hypothyroidism, carbon dioxide narcosis and hepatic or renal failure) should be excluded. Examples of diseases associated with or capable of causing permanent structural forebrain destruction include anencephaly and hydranencephaly, in which there is total loss or absence of the telencephalon; large, bilateral cerebral infarctions; hypoxic-ischemic encephalopathy following cardiac arrest; profound hypoglycemia; subarachnoid hemorrhage; "degenerative" diseases such as Alzheimer's disease; and some infectious and inflammatory diseases of the brain (e.g. Creutzfeldt-Jacob Disease and severe encephalitides). In each of these conditions the extent of the damage must be known to be sufficient to not allow recovery of forebrain function. We wish to emphasize that the diagnosis of these conditions is not, in itself, sufficient to establish the presence of a permanent vegetative state and, thus, to dictate management. It is vital to establish the extent and severity of disease. For example, a dementing individual may have Alzheimer's disease, but may be far from a permanent vegetative state.

The following approaches are considered:

\section{The Behavioral (Clinical) Approach}

Clinically, the patient with permanent vegetative state should not show a more complex response than simple eye opening, randomly looking about or blinking to threat or loud noises. There should be no behavioral phenomena that we associate with cognition, such as speech or response to commands. The recognition of the syndrome is not difficult, but how can we determine the extent and permanency of the forebrain damage?

A number of prospective clinical studies have established features which, taken together, allow some prediction of "good" and "poor" outcomes in traumatic and non-traumatic coma. 16,17,18,19,20.21,22,23,24,25 "Poor outcomes" are mainly equated with little or no likelihood of independent existence. ${ }^{24}$ Using various clinical algorithms the prediction of full recovery or severe incapacitation has been achieved with better than eighty per cent reliability in several conditions. ${ }^{16-25}$ However, reliable early clinical predictors that the vegetative state is permanent have not been established. "Poor outcome" patients 24,26 or "lower quality survivors" 22 are heterogenous groups with severe neurological disabilities; these classifications are not equivalent to the permanent vegetative state. Accurate prediction of PVS should be our object in these "survivors". In subsequent paragraphs, the difficulty in assessment of cerebral cortical function, especially in the absence of response, is discussed.

What is cognition? Cognitive ability includes awareness of oneself, including one's own mental activity, and the environment. The cognitive process is often tested by the response to a command: the command is interpreted and this information is transfered to the planning and motor systems of the brain which execute the response. (Other sensory modalities including visual, olfactory, gustatory and somatosensory can and perhaps should be used, as long as it is obvious that the patient can respond in a manner that indicates higher order recognition e.g. removing a noxious stimulus). Skultety ${ }^{27}$ argues that we should also consider the general "activation" of the cerebral hemispheres by the ascending reticular activating system, which also receives the sensory stimulus. Cognition involves perception, higher order information processing, including integration with memory and emotions, as well as generation of ideas and plans. The transformation, reduction, elaboration, storage, recovery and use of information, including previous knowledge, can take place even in the absence of continued stimulation.

How can we clinically exclude cognition or the potential for cognition? Even if there is no obvious relatively selective, severe dysfunction of the "efferent" or motor system, suçh as 
profound extra-pyramidal rigidity, locked-in syndrome or dysfunction of the lower motor units, our clinical study of behavior is at least a step away from studying perception and cognition: thought processes can go on without outward behavioral manifestations. It is possible to determine that an individual is capable of thought if he responds purposefully to stimulation, but we cannot conclusively demonstrate that cognitive processes are not going on in the absence of such behavior.

The above-mentioned clinical studies provide only an indirect assessment of the severity of the cerebral insult; for example, in one of the best studies in predicting responsive awakening after cardiac arrest, ${ }^{25}$ the predictive variables were: motor response, pupillary light reflex, spontaneous eye movements and serum glucose under $300 \mathrm{mg}$ per deciliter. The major difficulty is that we cannot, in the absence of motor response, clinically study the function of the large regions of the cerebral hemispheres where integration of sensory information, comprehension, generation of ideas and planning take place. We cannot clinically determine, in any direct manner, how completely or permanently they have been destroyed.

Thought, at its most basic level, is obvious only to the individual; clinically, we cannot adequately assess the dysfunction of this most highly prized brain activity.

\section{Investigative Tests}

By which other methods can we assess the extent of damage to the cerebral cortex or its connections, which is/are essential for cognitive processes?28 This cannot be adequately assessed clinically in the early part of the illness. To determine that the cerebral cortex has been totally, or essentially totally, and permanently rendered incapable of function we have to go beyond the clinical assessment, by the use of technologically sophisticated investigation.

Such investigative tests cannot directly examine thought, but they can assess its physiological basis, namely the function of the neurons in the cerebral cortex, as well as the gross structure of the cerebrum. Cerebral function can be assessed electrophysiologically, by blood flow determinations and by metabolic studies, while structure can be assessed by neuro-imaging techniques.

Brain death is the product of technological advancement, since its existence depends upon intensive care units with ventilators and methods of assisting circulation and treating complications. However, the diagnosis of brain death is dependent on clinical evaluation; specialized, "high tech" investigations are usually not required. ${ }^{3}$ In contrast, PVS is not always dependent on technology for its occurrence, yet the use of investigative equipment is necessary for its accurate prognosis.

\section{Electroencephalography}

As Pallis ${ }^{4}$ points out, the electroencephalogram (EEG) is not a good test for brain death, because it does not assess the brainstem, loss of function of which is the essential feature of brain death. However, the EEG is a good test of cerebral cortical function. Its physiological basis is the summated synaptic potentials of neurons, with glia playing only a passive, amplifying role secondary to neuronal activity. ${ }^{29}$

There is now reliable information regarding the prognostic significance of certain EEG patterns in hypoxic-ischemic encephalopathy after cardiac arrest. Binnie et al ${ }^{30}$ showed that outcome after cardiac arrest could be predicted by EEG alone in 92 of their 93 recordings with a confidence level of better than 99 per cent. Recordings performed 24-48 hours after cardiac arrest which show the following patterns have predictive value for failure to recover behavioral consciousness: iso-electric or burst-suppression $31-40$ or generalized, periodic sharp waves at intervals of 0.5-2.0 seconds with a suppressed background, usually in association with myoclonus. ${ }^{30,41,42,43}$ The iso-electric EEG (with no signals over 2 microvolts) is probably of greater predictive value than the others mentioned. ${ }^{32,44}$ Predictive value for other patterns is enhanced if a deterioration, e.g. burst-suppression to complete suppression, is found on serial recordings. ${ }^{34}$

Some patterns after cardiac arrest are usually, but not always, associated with an outcome no better than a permanent vegetative state. They are, therefore, not as definitive as those showing complete suppression: generalized epileptiform discharges such as groups of spikes or continuous spike-and-wave; alpha or theta coma pattern; persistent, diffuse, unreactive, low-amplitude, irregular delta activity. 30,33,34,45-49 Patients with these patterns should have serial recordings, as a more prognostically definitive pattern often evolves within several days of the first tracing. 35,47

Precautions are necessary when the EEG is used to predict outcome following cardiac arrest. There is a report of recovery of a patient after electrocerebral silence lasting up to one hour when recorded immediately after cardiac arrest; ${ }^{39}$ one patient, whose burst-suppression pattern was recorded within 24 hours post-arrest, recovered. 32 In the burst-suppression pattern, the suppression between bursts should be complete $e^{43}$ and longer than one second. ${ }^{35}$ Prediction of outcome using the EEG should await two or more recordings done more than 24 hours from the time of cardiac arrest. Patients should be normotensive and normothermic when recorded and they should not have anesthetic doses of medication, serious metabolic derangement, sepsis or active central nervous system disease other than the anoxicischemic insult.

The EEG has not been adequately evaluated as a prognostic test in other conditions which are capable of causing the permanent vegetative state. It will likely be more useful in those conditions causing neuronal death in the cerebral cortex (e.g. Creutzfeldt-Jakob disease) than in disorders associated with disconnections (e.g. trauma).

Cortical event-related potentials, an extension of EEG, hold promise as a means of assessing cerebral function. For example, bilateral absence of cortical (N19-P22) somatosensory evoked responses has predictive value for death or PVS. ${ }^{50}$ Further studies are needed, however, and the procedures require better standardization before they can be generally applied. It also remains to be seen whether such tests, which likely co-vary with the EEG, are superior to the latter.

\section{Cerebral Blood Flow and Metabolic Studies}

Regional cerebral blood flow ( $\mathrm{rCBF}$ ) scans and measurements of regional glucose (rCMRGlc) and oxygen metabolism $\left(\mathrm{rCMRO}_{2}\right)$ using positron emission tomography (PET), like the EEG, are tests of function. Timing is important with rCBF: shortly after coma onset, scans show marked variability. ${ }^{51}$ Later in the persistent vegetative state there is usually a reduction in these activities in the forebrain, but considerable inter-individual 
variation persists. 52 Measurements of global cerebral oxygen metabolism and CMRClc are reduced to about $40-60$ per cent of normal in the persistent vegetative state. $53.55 \mathrm{~A}$ concern is that neuronal metabolism probably accounts for only about 50-65 per cent of normal brain oxygen and glucose utilization. 54 Thus, these measures lack the specificity of the EEG, which more specifically reflects neuronal activity. Although it is speculated that the above reduction in these functions represents selective neuronal damage, ${ }^{55}$ can this be assumed in the individual case? Although these tests assist the study of such patients and help in the differential diagnosis of the locked-in syndrome, they are available in a small number of centres and are not well standardized. Thus, they seem of little practical value.

There is some promise in a newer technique which uses complex, lipophilic molecules coupled to radioisotopes, such as hexamethylpropyleneamineoxime (HMPAO). 55 These compounds show a high penetration into the brain parenchyma in the first pass through the brain capillaries. The compound changes its steric configuration once in the brain, preventing diffusion back into the blood. The concentration of the compound in the brain, as reflected by the regional changes in radioactivity, is determined by regional cerebral blood flow which, in turn, is dependent on regional metabolic activity. The widespread availability of such agents along with imaging technology, especially single photon emission computerized tomography (SPECT), is an imminent reality. Further improvements in the labelled compound and in imaging may lead to a more reliable test of cortical function. The same theoretical limitations as with rCBF, rCMRGlc and rCMRO $_{2}$ apply, however. Further longitudinal studies are needed to determine outcome and pathological correlation.

Cerebrospinal fluid levels of lactate, glutathione and adenylate kinase have been measured after cardiac arrest. 56 Lactate and/or glutathione levels at 24 and 48 hours, respectively, were significantly higher in those who died early than in longer survivors. These should be studied in PVS, but the large variation of values in the published study is discouraging that these tests will be very useful.

\section{Neuro-Imaging}

Use of the CT scan and MRI to assess the structural integrity of the brain has obvious attraction. Shortly after an anoxicischemic insult, a variety of changes may occur including effacement of cortical sulci, loss of grey-white differentiation, basal ganglia lesions or selective enhancement of the cerebral cortex, basal ganglia or both. ${ }^{57}$ Thus far, these early findings have not been of proven prognostic reliability, but further study is needed. Late changes may prove more definitive, but they would be less clinically valuable.

\section{Significance and Management of Brain Death and the Persistent Vegetative State}

Brainstem death is equivalent to brain death, which is legally regarded as death of the individual. Neurologically, individuals with the persistent vegetative state are not brainstem dead. Since the brainstem is relatively intact (in contrast to the cerebrum), such individuals maintain vegetative and homeostatic functions such as spontaneous ventilation, coughing, swallowing and regulation of temperature and respiration. No society would consider these individuals as "dead"; the thought of burying or transplanting vital organs from such individuals is morally repugnant. ${ }^{1}$ Either course would be regarded as equivalent to homocide. ${ }^{58}$ The transplantation of organs from anencephalic infants remains controversial - are they special cases who should be considered separately from other PVS patients? This topic deserves a separate paper for discussion.

It is vital that the diagnosis of intractable coma and permanent vegetative state be accurate. 5 Potential for recovery as in some previous cases of "persistent vegetative state" should be excluded.

Thought is the most highly prized activity of the human brain, as reflected in Descartes' statement, "Cogito, ergo sum" (I think, therefore, I am). 59 Our society has adopted this Cartesian philosophy; cognition is regarded as the essential human quality. When cognitive capacity is totally and forever lost, as in intractable coma and the permanent vegetative state, it is generally agreed that use of intensive care units is not justified to needlessly prolong such a low quality of life. ${ }^{60}$ Such an existence serves no purpose to the individual and it places great stresses and burdens on families and society. This position is supported by the recommendations of the President's Commission for the Study of Ethical Problems in Medicine and Biomedical and Behavioral Research in the United States. ${ }^{61}$

Having stated the above, management of patients with PVS can take different levels of care, depending on known preferences of the patient and family. Advance directives from the patient in the form of previously spoken or written statements should be considered. In addition, or in the absence of advance directives, family preferences should be identified. It should be assured that comfort, dignity and hygiene are maintained. In some situations, e.g. if family members cannot agree, referral for judicial review is necessary. Management of cases of PVS should be regularly reviewed by hospital ethics committees.

\section{Conclusions and Suggestions}

1. Cognitive function is the most valued human quality; when the potential for cognition is totally and permanently absent, prolonging the existence of the body is not socially desirable or necessary. The only conditions which meet the qualifications for lasting absence of cognitive ability are brain death, intractable coma and the persistent (permanent) vegetative state.

2. Although the diagnosis of PVS is made clinically, determination of the prognosis requires clinical assessment and investigative tests. Establishing irreversibility requires an etiology which is capable of causing structural forebrain damage. To establish that such damage is sufficient to preclude the return of cognitive function, investigative tests should examine the function and structure of the cerebral hemispheres and should be available in most tertiary care referral centres. The EEG is the most specific available test of cortical neuronal function, and has proven prognostic reliability in anoxic-ischemic encephalopathy. Event related potentials hold promise but require further study and standardization of technique. The lise of SPECT scans with a special lipophilic agent linked to a radioisotope, such as $99 \mathrm{mTc}-\mathrm{HMPAO}$, is an available test of brain function that requires further development and assessment. The CT and MRI scans are suitable tests of structure. 
3. Management of brain death and PVS are very different. Patients with brain death are legally dead and their organs can be transplanted if consent is obtained. Those with PVS are not legally dead; after the diagnosis and prognosis are established, the level of care is decided upon using advance directives and family preferences. In some cases hospital ethics committees or the courts may need to decide the level of care.

\section{REFERENCES}

1. Lamb D. Brain death and ethics. Albany: SUNY Press 1985.

2. Pallis $\mathrm{C}$. Whole brain death reconsidered-physiological facts and philosophy. J Med Ethics 1983; 9: 32-37.

3. Guidelines for the diagnosis of brain death. Can J Neurol Sci 1987; 13: 355-358.

4. Pallis C. ABC of Brainstem Death. London: British Medical Journal 1983.

5. Cranford RE. The persistent vegetative state: getting the facts straight. Hastings Center Report 1988; 18: 27-32.

6. Plum F, Posner JB. The diagnosis of stupor and coma. Philadelphia: FA Davis 1980; 3.

7. Jennett WB, Plum $F$. The persistent vegetative state: a syndrome in search of a name. Lancet 1972; 1: 734-737.

8. Armstrong PW, Colen BD. From Quinlan to Jobes: the courts and the PVS patient. Hastings Center Report 1988; 18: 37-40.

9. Brierley JB, Adams JH, Graham DI, et al. Neocortical death after cardiac arrest. Lancet $1971 ; 2: 560-565$.

10. Dougherty JH Jr., Rawlinson D, Levy DE, et al. Hypoxic-ischemic brain injury and the persistent vegetative state. Clinical and neuropathological correlation. Neurology 1979; 29: 591.

11. Ingvar DH, Brun A, Johansson L, et al. Survival after severe cerebral anoxia with destruction of the cerebral cortex: the appalic syndrome. $\ln$ : Korein S, ed. Brain Death: Interrelated Medical and Social Issues. Ann NY Acad Sci 1978; 315: 184-214.

12. Wolf SM. The persistent problem of PVS. Hastings Center Report 1988; 18: 26

13. Rosenberg GA, Johmnson SF, Brenner RP. Recovery of cognition after prolonged vegetative state. Ann Neurol 1977; 2: 167-168.

14. Plum F, Posner JB. The diagnosis of stupor and coma. Philadelphia: FA Davis 1980; 340.

15. Shuttleworth E. Recovery to social and economic independence from prolonged postanoxic vegetative state. Neurology 1983; 33: 372-374.

16. Teasdale G, Jennett B. Assessment of coma and impaired consciousness: a practical scale. Lancet 1974; 2: 81-84.

17. Willoughby JO, Leach BG. Relation of neurologic findings after cardiac arrest to outcome. Br Med J 1974; 3: 437-439.

18. Jennett B, Bond M. Assessment of outcome after severe brain damage: a practical scale $1975 ; 1: 480-484$.

19. Bates D, Caronna JJ, Cartlidge NEF, et al. A prospective study of nontraumatic coma: methods and results in 310 patients. Ann Neurol 1977; 2: 211-220.

20. Finkelstein S, Caronna JJ. Outcome of coma following cardiac arrest. Neurology (Minneap) 1977; 27: 367-368.

21. Levy DE, Knill-Jones RP, Plum F. The vegetative state and its prognosis after non-tramatic coma. Ann NY Acad Sci 1978; 315 : 293-306.

22. Eamest MP, Breckinridge JC, Yarnell PR, et al. Quality of survival after out-of-hospital cardiac arrest: predictive value of early neurologic evaluation. Neurology (Minneap) 1979; 29; 56-60.

23. Snyder BD, Loewenson RB, Gumnit RJ, et al. Neurologic prognosis after cardiac arrest: II. Level of consciousness. Neurology (Minneap) 1980; 30: 52-58.

24. Levy DE, Bates D, Caronna JJ, et al. Prognosis of nontraumatic coma. Ann Int Med 1981; 94: 293-301.

25. Longstreith WT, Diehr P, Inui TS. Prediction of awakening after out-of-hospital cardiac arrest. N Eng J Med 1983; 308: 13781382.

26. Teasdale G, Knill-Jones R, Van der Slade J. Observer variability in assessing impaired consciousness and coma. J Neurol Neurosurg Psychiatry 1978; 41: 603-610.
27. Skultety FM. Clinical and experimental aspects of akinetic mutism: report of a case. Arch Neurol 1968; 19: 1-14.

28. Churchland PS, Sejnowski TJ. Perspectives on cognitive neuroscience. Science 1988; 242: 741-745.

29. Speckmann E-J, Elger CE. Introduction to the neurophysiological basis of the EEG and DC potentials. In: Niedermeyer E, Lopes da Silva F. eds. Electroencephalography: Basic Principles, Clinical Applications and Related Fields. Baltimore, Munich: Urban and Schwarzenberg 1987; 1-14.

30. Binnie CD, Prior PF, Lloyd DSL, et al. Electroencephalographic prediction of fatal anoxic brain damage after resuscitation from cardiac arrest. Br Med J 1970; 4: 265-268.

31. Bickford RG, Dawson B, Takeshita H. EEG evidence of neurologic death. Electroenceph Clin Neurophysiol 1965; 18: 513-514.

32. Hockaday JM, Potts F, Epstein E, et al. Electroencephalographic changes in acute cerebral anoxia from cardiac or respiratory arrest. Electroencephalogr Clin Neurophysiol 1965; 18: 575-586.

33. Pampliglione G, Harden A. Resuscitation after cardiac arrest: prognostic value of early electroencephalographic findings. Lancet 1968; 1: 1261-1264.

34. Prior PF. The EEG in acute cerebral anoxia. Amsterdam: Excerpta Medica 1973.

35. Moller M, Holm B, Sindrup E, et al. Electroencephalographic prediction of anoxic brain damage after resuscitation from cardiac arrest in patients with acute myocardial infarction. Acta Med Scand 1978; 203: 31-37.

36. Saunders MG, Westmoreland BF. The EEG in evaluation of disorders affecting the brain diffusely. In: Klass $\mathrm{D}$, Daly DD, eds. Current Practice of Clinical Electroencephalography. New York: Raven Press 1979; 349-352.

37. Kuroiwa Y, Celesia GG, Clinical significance of periodic EEG patterns. Arch Neurol (Chic) 1980; 37: 15-19.

38. McCarty GE, Marshall DW. Transient eyelid opening associated with postanoxic EEG burst-suppression pattern. Arch Neurol 1981; 38: 754-756.

39. Markand ON. EEG in diffuse encephalopathies. J Clin Neurophysiol 1984; 1: 357-407.

40. Krumholz A, Stem BJ, Weiss HD. Outcome from coma after cardiopulmonary resuscitation: relation to seizures and myoclonus. Neurology 1988; 38: 401-405.

41. Gaches J. Activites periodiques en E.E.G. Rev EEG Neurophysiol 1971; 1:9-33.

42. Nilsson BY, Olsson Y, Sourander P. Electroencephalographic and histopathological changes resembling Jakob-Creutzfeldt disease after transient cerebral ischemia due to cardiac arrest. Acta Neurol Scand 1972; 48: 416-426.

43. Kuroiwa Y, Celesia GG, Chung HD. Periodic EEG changes and status spongiosus of the cerebral cortex in anoxic encephalopathy: a necropsy case report. J Neurol Neurosurg Psychiatry 1982; 45: 740-742.

44. Sharbrough FW. Nonspecific EEG patterns. In: Niedermeyer E, Lopes de Silva F, eds. Electroencephalography. Basic Principles, Clinical Applications and Related Fields. Baltimore: Uraban and Schwarzenberg 1987; 13: 173 .

45. Madison D, Niedermeyer E. Epileptic seizures resulting from acute cerebral anoxia. J Neurol Neurosurg Psychiatry 1970; 33: 381386.

46. Saunders MG, Westmoreland BF. The EEG in evaluation of disorders affecting the brain diffusely. $I n$ : Klass DW, Daly DD, eds. Current Practice of Clinical Electroencephalography. New York: Raven Press 1979; 343-379.

47. Young GB, Blume WT, Jacono V, et al. Alpha-theta coma: critical timing of the second EEG. American EEG Society Meeting: Orlando 1985.

48. Austin EJ, Wilkus RJ, Longstreth WT. Etiology and prognosis of alpha coma. Neurology 1988; 38: 733-777.

49. Synek VM. Prognostically important patterns in diffuse anoxic and traumatic encephalopathies in adults. J Clin Neurophysiol 1988; 5: $161-174$.

50. Eisen A, Aminoff A. Somatosensory evoked potentials. In: Aminoff MJ, ed. Electrodiagnosis in Clinical Neurology, Second 
Edition. London: Churchill Livingstone 1986; 560-561.

51. Deutsch G, Eisenberg HM. Frontal blood flow changes in recovery from coma. J Cerb Blood Flow Metab 1987; 7: 29-34.

52. Levy DE, Sidtis JJ, Rottenberg DA, et al. Differences in cerebral blood flow and glucose utilization in vegetative versus locked-in patients. Ann Neurol 1987; 22: 673-682.

53. Shalit MN, Beller AJ, Feinsod M. Clinical equivalents of cerebral oxygen consumption in coma. Neurology 1972; 20: 740-748.

54. Hertz L, Schousboe A. Ion and energy metabolism of the brain at a cellular level. Int Rev Neurobiol 1975; 18: 141-211.

55. Abdel-Dayem HM, Sadek SA, Kouris KM, et al. Changes in cerebral perfusion after acute head injury: comparison of CT with Tc-99m HM-PAO SPECT. Radiology 1987; 165: 221-226.
56. Edgren E, Hedstrand U, Nordin M, et al. Prediction of outcome after cardiac arrest. Crit Care Med 1987; 15: 820-825.

57. Kjos BO, Brant-Zawadzki M, Young RG. Early CT findings of global central nervous system hypoperfusion. AJR 1983; 141: $1227-1232$.

58. Capron AM. Anencephalic donors: separate the dead from the dying. Hastings Center Report 1987; 17: 5-9.

59. Copleston F. A history of philosophy. Book II. New York: Image Books 1963; 90-115.

60. Brody BA. Ethical questions raised by the persistent vegetative patient. Hastings Center Report 1988; 18: 33-37.

61. Abram MB, et al. Deciding to forgo life sustaining treatment. U.S. Government Printing Office; March 1983. 